\title{
Exigência de metionina + cistina para frangas de reposição na fase cria de sete a 12 semanas de idade
}

\author{
[Requirement of methionine + cystine for pullets in the growing \\ phase from 7 to 12 weeks old] \\ P. D'Agostini, P.C. Gomes, A.A. Calderano, H.H.C. Mello, L.M. Sá, H.S. Rostagno, L.F.T. Albino \\ Universidade Federal de Viçosa - Viçosa, MG
}

\begin{abstract}
RESUMO
Determinou-se a exigência de metionina + cistina para frangas de sete a 12 semanas de idade e verificouse seu efeito sobre a fase de postura. $\mathrm{O}$ experimento foi dividido em duas fases, de cria e de produção, esta de 22 a 33 semanas de idade. Na primeira fase, utilizaram-se 640 aves - 50\% Lohmann LSL e 50\% Lohmann Brown - com sete a 12 semanas de idade, distribuídas em delineamento inteiramente ao acaso, em esquema fatorial $5 \times 2$ (porcentagem de met+cis e linhagem), com quatro repetições e 16 aves por repetição. As porcentagens de met+cis total estudadas foram 0,$471 ; 0,541 ; 0,611 ; 0,681$ e $0,751 \%$. Ao atingirem 22 semanas de idade, 240 aves foram utilizadas para verificar o efeito residual das dietas fornecidas na fase de cria. A dieta fornecida nesta fase foi igual para todas as aves. As exigências de metionina + cistina para aves de reposição, leves e semipesadas, no período de sete a 12 semanas de idade, foram de $0,710 \%$ de met+cis total $(0,639 \%$ de met+cis digestível $)$ e $0,706 \%$ de met+cis total $(0,635 \%$ de met+cis digestível), respectivamente.
\end{abstract}

Palavras-chave: aminoácidos, ovo, maturidade sexual, poedeira, requisito

\begin{abstract}
The methionine + cystine requirement was determined for pullets from seven to 12 weeks of age and its effect was verified on the laying phase. The experiment was divided into two phases, growing and production, which lasted from 22 to 33 weeks of age. In the first experimental phase we used 640 birds (50\% and 50\% Lohmann LSL Lohmann Brown) allotted in a completely randomized factorial scheme 5x2 (methionine + cystine levels and lineages), with four replications and 16 birds per repetition. The levels of total methionine + cystine studied were $0.471 ; 0.541 ; 0.611 ; 0.681$ e $0.751 \%$. When they reached 22 weeks of age, 240 birds were used to verify the residual effect of the diets fed during the growth period. The level of methionine + cystine for white-egg and brown-egg pullets in the period from 1 to 6 weeks of age were $0.710 \%$ of total methionine + cystine $(0.639 \%$ met+cis digestible) and $0.706 \%$ of total methionine + cystine $(0.635 \%$ of met + cis digestible $)$, respectively.
\end{abstract}

Keywords: amino acids, egg, hen, requirements, sexual maturity

\section{INTRODUÇÃO}

A deficiência de nutrientes nos estádios iniciais do crescimento é crítica para o desenvolvimento de tecidos específicos do corpo de uma ave. Segundo Kwakkel (1992), a poedeira atinge $82 \%$ do seu peso adulto às 15 semanas, sendo que a proteína é depositada, principalmente, nos músculos e no trato digestivo, e a gordura no tecido intramuscular. Entretanto, a eficiência de aproveitamento da proteína pelo organismo das aves depende da composição e da quantidade de aminoácidos essenciais presentes na dieta, entre eles a metionina e metionina + cistina, pois a metionina é considerada aminoácido limitante para aves (Bredford e Summers, 1985).

Recebido em 22 de agosto de 2011

Aceito em 20 de julho de 2012

E-mail: priscila.agostini@ technofeed.com.br 
A atualização das exigências nutricionais de aminoácidos sulfurosos para as aves de reposição justifica-se pelo melhoramento contínuo das linhagens, em virtude de novos produtos genéticos com características de produção superiores aos já existentes serem, constantemente, lançados no mercado. No entanto, o número de pesquisas desenvolvidas para a determinação das exigências nutricionais em aminoácidos é escasso se forem considerados os avanços no melhoramento genético que as aves vêm sofrendo nos últimos anos, bem como os novos conhecimentos nas áreas de nutrição, manejo e ambiência.

Segundo Baker (1986), aves mais pesadas exigem maior quantidade de cada nutriente essencial, em comparação às leves, mas evidências sugerem que as exigências expressas, como porcentagem ou miligrama por quilograma da ração, não variam, ou são inferiores, às propostas para poedeiras leves de mesma idade. O que se observa, contudo, na prática é que a exigência de aves semipesadas é atendida com o aumento do consumo de ração.

As estimativas das exigências de aminoácidos para aves de postura são afetadas por uma complexidade de fatores, como idade, ambiente e vários outros de ordem nutricional, bem como o constante melhoramento genético, sendo necessária a atualização de seus valores.

Objetivou-se determinar as exigências nutricionais em aminoácidos sulfurosos para frangas de reposição na fase de sete a 12 semanas de idade, de linhagens comerciais, e verificar seu efeito sobre a fase de postura de 22 a 33 semanas de idade.

\section{MATERIAL E MÉTODOS}

Para a determinação da exigência de metionina + cistina para frangas de sete a 12 semanas de idade das linhagens comerciais Lohmann LSL e Lohmann Brown, o experimento foi dividido em duas fases experimentais, sendo a primeira a fase de cria de sete a 12 semanas de idade, em que se avaliaram as características de desempenho consumo de ração, conversão alimentar e ganho de peso -, e a segunda fase a de produção -22 a 33 semanas de idade -, em que se avaliaram as características de desempenho - consumo de ração, conversão alimentar e porcentagem de postura - e de qualidade do ovo.

As aves foram criadas, até atingirem sete semanas de idade, em galpões de recria e receberam ração e água à vontade. A dieta para esta fase foi formulada de acordo com as recomendações de Rostagno et al. (2000). Todas as aves foram debicadas aos 10 dias de idade, e foi adotado o manejo de vacinação para controle das principais enfermidades presentes nas aves de postura.

Ao atingirem a idade de sete semanas de idade, foram transferidas para as instalações experimentais, onde foram pesadas e alojadas em boxes telados, compostos de lâmpada, cama de maravalha, bebedouro nipple e comedouro pendular. O peso médio, por ave, no início de experimento foi de $328,7 \mathrm{~g}$ para frangas leves e de $378,1 \mathrm{~g}$ para semipesadas.

Para a determinação da exigência de metionina + cistina (met+cis) na fase cria de frangas de postura, foram utilizadas 640 aves de reposição fêmeas, sendo 320 aves leves da marca comercial Lohmann LSL e 320 aves semipesadas da marca comercial Lohmann Brown. O delineamento experimental utilizado foi o inteiramente ao acaso, em esquema fatorial $5 \times 2$, sendo cinco porcentagens de inclusão de met+cis e dois tipos de aves - leves e semipesadas -, com quatro repetições por tratamento e 16 aves por unidade experimental.

Foram fornecidas rações isocalóricas e isoproteicas, variando apenas os níveis de met+cis. As dietas experimentais foram obtidas a partir de uma dieta basal (Tab. 1), suplementada com cinco porcentagens de DL-Metionina (99\%), de forma a proporcionar 0,$471 ; 0,541$; 0,$611 ; 0,681$ e $0,751 \%$ de met+cis total. A suplementação com DL-Metionina foi feita em substituição ao amido, assegurando, com isso, que as rações permanecessem isoproteicas e isoenergéticas. Os demais nutrientes contidos nas rações foram utilizados atendendo às recomendações de Rostagno et al. (2000).

A água e a ração foram fornecidas à vontade. 
Tabela 1. Composição percentual da ração e valor nutricional para frangas de reposição leves e semipesadas de sete a 12 semanas de idade

\begin{tabular}{|c|c|}
\hline Ingrediente & $\%$ \\
\hline Farelo de soja & 27,17 \\
\hline Raspa de mandioca & 35,19 \\
\hline Sorgo & 31,00 \\
\hline Farelo de trigo & 0,200 \\
\hline Óleo vegetal & 2,20 \\
\hline Fosfato bicálcico & 1,65 \\
\hline Calcário & 0,74 \\
\hline Sal & 0,285 \\
\hline Suplemento vitamínico ${ }^{1}$ & 0,10 \\
\hline Suplemento mineral ${ }^{2}$ & 0,05 \\
\hline Antioxidante $^{3}$ & 0,01 \\
\hline Virginamicina $50 \%$ & 0,002 \\
\hline Cloreto de colina $60 \%$ & 0,042 \\
\hline Salinomicina $12 \%^{4}$ & 0,035 \\
\hline Amido & 1,326 \\
\hline Total & 100 \\
\hline \multicolumn{2}{|l|}{ Composição } \\
\hline Energia metabolizável, kcal/ kg & 2.906 \\
\hline Proteína bruta, $\%$ & 18,36 \\
\hline Metionina + cistina total,$\%$ & 0,536 \\
\hline $\begin{array}{l}\text { Metionina + cistina digestíveis, } \\
\%\end{array}$ & 4,70 \\
\hline Lisina, $\%$ & 1,02 \\
\hline Cálcio, \% & 0,946 \\
\hline Fósforo disponível, \% & 0,44 \\
\hline \multicolumn{2}{|c|}{$\begin{array}{l}{ }^{1} \text { Rovimix (Roche) - kg do produto: vit. A - } 10.000 .000 \mathrm{UI} \text {; vit. } \\
\text { D3 - 2.000.000UI; vit. E - } 30.000 \mathrm{UI} \text {; vit. B1 - 2,0g; vit. B6 } \\
\text { 4,0g; ác. pantotênico - 12,0g; biotina - 0,10g; vit. K3 - 3,0g; } \\
\text { ácido fólico - 1,0g; ácido nicotínico - 50,0g; vit. B12 } \\
\text { 15.000mcg; Se - 0, 25g. } \\
{ }^{2} \text { Roligomix (Roche) - kg do produto: Mn } 16,0 \mathrm{~g} \text {; Fe - } 100,0 \mathrm{~g} \text {; } \\
\mathrm{Zn}-100,0 \mathrm{~g} \text {; Cu - 20,0g ; Co - 2,0g; I - 2,0g. } \\
{ }^{3} \text { Hidroxibutiltolueno. } \\
{ }^{4} \text { Anticoccidiano. }\end{array}$} \\
\hline
\end{tabular}

A temperatura no galpão foi monitorada três vezes ao dia, por meio de três termômetros de máxima e mínima, distribuídos ao longo do galpão, posicionado à altura das aves. As temperaturas médias mínima e máxima foram 21 e $29^{\circ} \mathrm{C}$, respectivamente.

As variáveis avaliadas nesta fase foram consumo de ração, ganho de peso e conversão alimentar. As aves e a ração foram pesadas no início e no final do período experimental, permitindo a determinação do ganho de peso e da quantidade de ração consumida. Ao final do período experimental, as aves foram transferidas para o galpão de postura, onde permaneceram durante toda a fase de produção e receberam todos os cuidados sanitários. Além disso, o fornecimento de ração foi à vontade, sendo que a ração foi balanceada para todos os nutrientes, formulada de acordo com as recomendações de Rostagno et al. (2000).

Ao completarem 18 semanas de idade, iniciou-se o programa de luz, quando as aves receberam 15 horas de luz; ao atingirem 20 semanas de idade, receberam 16 horas de luz; ao completarem 22 semanas de idade, 17 horas de luz. A partir de 22 semanas de idade, o fornecimento de 17 horas de luz foi constante.

Ao atingirem 22 semanas de idade, iniciou-se a segunda fase experimental, sendo utilizadas 120 frangas da marca comercial Lohmann LSL e 120 da marca comercial Lohmann Brown, provenientes da primeira fase experimental. Inicialmente, as aves foram separadas por tratamento (referente à primeira fase experimental) e, posteriormente, foram pesadas e alojadas nas gaiolas de forma a garantir o peso médio por repetição dentro de cada tratamento. $\mathrm{Na}$ fase de produção, foram avaliados os efeitos da porcentagem de met+cis fornecida no período de sete a 12 semanas de idade sobre as variáveis produtivas.

O delineamento utilizado foi inteiramente ao acaso, em esquema fatorial $5 \times 2$, sendo cinco porcentagens de inclusão de aminoácidos sulfurados e dois tipos de aves - leves e semipesadas -, com quatro repetições e seis aves por unidade experimental. A ração fornecida nesta fase foi a mesma para todos os tratamentos, pois o objetivo era avaliar o efeito dos tratamentos (rações) aplicados no período de sete a 12 semanas de idade. A dieta atendeu às exigências nutricionais das aves, segundo as recomendações de Rostagno et al. (2000), contendo $2.800 \mathrm{kcal} / \mathrm{kg}$ de EM, $16 \%$ de PB, $4,02 \%$ de $\mathrm{Ca}$ e $0,377 \%$ de $\mathrm{Pd}$.

As temperaturas médias mínima e máxima no galpão foram, respectivamente, 14,4 e $28,8^{\circ} \mathrm{C}$. 
Na fase de produção, foram avaliados os efeitos da porcentagem de inclusão de met+cis fornecida no período de sete a 12 semanas de idade sobre as características produtivas. As variáveis avaliadas foram: média, em dias, em que as aves atingiram $50 \%$ de produção em cada parcela experimental, produção de ovos, consumo alimentar, conversão alimentar, peso médio dos ovos, peso médio dos componentes dos ovos, unidade Haugh (UH).

Análises de regressão polinomial foram usadas conforme o ajustamento dos dados obtidos para cada variável, utilizando-se o programa SAEG (Sistema..., 1999).

\section{RESULTADOS E DISCUSSÃO}

O aumento da porcentagem de inclusão de met+cis nas rações proporcionou aumento no ganho de peso das aves leves e semipesadas na fase de cria $(\mathrm{P}<0,01)$ (Tab. 2). Nesta fase, as aves responderam positivamente ao aumento de met+cis na ração, apresentando maior ganho de peso com 0,710 e $0,703 \%$ de met+cis, respectivamente, para leves e semipesadas.

Foi observado efeito linear da porcentagem de met+cis sobre o consumo de ração tanto para aves leves quanto para semipesadas. Para aves semipesadas, houve redução no consumo de ração à medida que se elevou o nível de suplementação $(\mathrm{P}<0,05)$, enquanto para aves leves houve aumento. No entanto, é importante ressaltar que o $\mathrm{R}^{2}$ de ambas as equações foi baixo (Tab. 3).

A inclusão de met+cis nas rações influenciou a conversão alimentar de forma quadrática tanto para aves leves quanto para semipesadas, sendo a inclusão de 0,702 e $0,706 \%$ de met+cis, respectivamente, a que resultou em melhores resultados (Tab. 3).

Tabela 2. Características de desempenho de frangas de reposição leves (L) e semipesadas (SP), no período de sete a 12 semanas de idade, em razão da porcentagem de metionina + cistina nas rações

\begin{tabular}{|c|c|c|c|c|c|c|}
\hline \multirow{3}{*}{$\begin{array}{c}\text { Met+cis } \\
(\%)\end{array}$} & \multicolumn{6}{|c|}{ Características } \\
\hline & \multicolumn{2}{|c|}{ Ganho de peso (g) } & \multicolumn{2}{|c|}{ Consumo de ração $(\mathrm{g})$} & \multicolumn{2}{|c|}{ Conversão alimentar } \\
\hline & $\mathrm{L}$ & SP & $\mathrm{L}$ & SP & $\mathrm{L}$ & SP \\
\hline 0,471 & 392 & 482 & 1,799 & 2,172 & 4,596 & 4,515 \\
\hline 0,541 & 452 & 577 & 1,863 & 2,207 & 4,132 & 3,829 \\
\hline 0,611 & 475 & 612 & 1,865 & 2,122 & 3,937 & 3,467 \\
\hline 0,681 & 489 & 634 & 1,888 & 2,090 & 3,867 & 3,294 \\
\hline 0,751 & 493 & 637 & 1,886 & 2,091 & 3,828 & 3,283 \\
\hline Média & $460 \mathrm{~b}$ & $588 \mathrm{a}$ & $1,860 \mathrm{~b}$ & $2,136 \mathrm{a}$ & $4,072 \mathrm{a}$ & $3,678 b$ \\
\hline & & & Efeito & & & \\
\hline Linear & $*$ & $*$ & $* *$ & $* *$ & * & $*$ \\
\hline Quadrático & $*$ & $*$ & ns & ns & $* *$ & $*$ \\
\hline Interação & \multicolumn{2}{|c|}{$*$} & \multicolumn{2}{|c|}{$*$} & \multicolumn{2}{|c|}{$* *$} \\
\hline $\mathrm{CV}(\%)$ & \multicolumn{2}{|c|}{2,24} & \multicolumn{2}{|c|}{2,76} & \multicolumn{2}{|c|}{4,32} \\
\hline
\end{tabular}

Valores seguidos por letras diferentes na mesma linha diferem entre si pelo teste $\mathrm{F}(\mathrm{P}<0,05)$.

$*(\mathrm{P}<0,01) ; * *(\mathrm{P}<0,05) ; \mathrm{ns}(\mathrm{P}>0,05)$.

O consumo de ração, o ganho de peso e a conversão alimentar variaram entre as linhagens $(\mathrm{P}<0,01)$, isto é, as semipesadas consumiram $12,9 \%$ a mais em relação às leves, ganharam $21,77 \%$ mais peso e apresentaram conversão alimentar 9,67\% menor. O maior consumo de ração, o maior ganho de peso e a melhor conversão alimentar das aves semipesadas em relação às aves leves confirmam os resultados já obtidos por Rombola et al. (2008).

Embora tenha havido diferenças no desempenho entre as linhagens, a exigência de met+cis total das aves nesta fase de crescimento foi semelhante para as duas linhagens estudadas. 
Exigência de metionina...

Tabela 3. Equações de regressão dos modelos quadrático e linear e exigências nutricionais estimadas

\begin{tabular}{|c|c|c|c|c|}
\hline Parâmetro & Equação & $\begin{array}{c}\text { Exigência } \\
(\%)\end{array}$ & $\mathrm{R}^{2}$ & SQD \\
\hline \multicolumn{5}{|c|}{ Leves } \\
\hline \multicolumn{5}{|l|}{ Quadrático } \\
\hline Ganho de peso & $Y=-383,4+2477,6 x-1749 x^{2}$ & 0,710 & 0,99 & 0,00008 \\
\hline Conversão alimentar & $Y=10,824-19,986 x+14,249 x^{2}$ & 0,702 & 0,99 & 0,00565 \\
\hline \multicolumn{5}{|l|}{ Linear } \\
\hline Consumo de ração & $Y=1,6868+0,28357 x$ & $>0,751$ & 0,28 & 0,0403 \\
\hline \multicolumn{5}{|c|}{ Semipesadas } \\
\hline \multicolumn{5}{|l|}{ Quadrático } \\
\hline Ganho de peso & $Y=-786,4+4066,5 x-2897 x^{2}$ & 0,703 & 0,99 & 0,00019 \\
\hline Conversão alimentar & $Y=14,455-31,715 x+22,449 x^{2}$ & 0,706 & 0,99 & 0,0028 \\
\hline \multicolumn{5}{|l|}{ Linear } \\
\hline Consumo de ração & $Y=2,3803-0,39929 x$ & $<0,471$ & 0,32 & 0,06778 \\
\hline
\end{tabular}

SQD: Soma dos Quadrados dos Desvios.

A porcentagem de inclusão de met+cis na ração influenciou a média, em dias, em que as aves atingiram $50 \%$ de produção. Aves leves alimentadas com 0,611 a $0,751 \%$ de met+cis na fase de cria atingiram $50 \%$ de produção precocemente, aos 147 dias de idade, em relação àquelas que receberam rações com porcentagens mais baixas de met+cis. Foi verificado maior atraso na postura nas aves que receberam $0,471 \%$ de met+cis, as quais somente atingiram $50 \%$ de produção aos 152 dias de idade.

As aves semipesadas alimentadas, durante a fase de cria, com as porcentagens superiores a $0,541 \%$ de met+cis atingiram $50 \%$ de produção aos 149 dias de idade, e as que receberam $0,471 \%$ de met+cis somente atingiram $50 \%$ da produção aos 154 dias de idade. Estes resultados estão de acordo com Silva et al. (2009), os quais afirmaram que aves mais bem nutridas na fase de crescimento iniciam a postura mais cedo que aves submetidas à restrição nutricional.

O fornecimento de níveis de $0,471 \%$ met+cis em frangas de reposição semipesadas proporcionou atraso na produção de ovos quando comparado aos manuais das linhagens Lohmann LSL e Brown, que indicam $50 \%$ de produção das aves, em média, entre 21 e 22 semanas de idade. Este atraso se deve, provavelmente, ao atraso na maturação do sistema reprodutivo da ave, pois, durante a fase de produção, não se verificou variação no peso inicial das aves entre os tratamentos, descartando, desta forma, o efeito do peso corporal sobre o desempenho ocasionado nesta fase. Logo, verificou-se que a deficiência em aminoácidos sulfurosos durante a fase de sete a 12 semanas de idade ocasionou retardo no desenvolvimento do aparelho reprodutivo da ave, levando ao aumento na idade de produção.

Os níveis de met+cis fornecidos durante a fase de cria não influenciaram o consumo de ração, a conversão alimentar e a produção de ovos das aves durante a fase de produção, compreendida entre 22 e 33 semanas de idade ( $\mathrm{P}>0,05)$ (Tab.4). Desta forma, pode-se inferir que aves que receberam deficiência desses aminoácidos, no período de sete a 12 semanas de idade, tiveram uma recuperação na fase subsequente, e durante a fase de postura não apresentaram efeito residual da inclusão de met+cis na ração de cria.

As aves leves consumiram menor quantidade de ração e apresentaram maior conversão alimentar por dúzia de ovos produzidos em relação às aves semipesadas. Quando se considera a conversão alimentar por massa de ovos, não houve diferença entre as duas linhagens. Isso se deve ao fato de as aves leves produzirem ovos mais leves em relação às aves semipesadas, portanto, para uma mesma massa de ovos, é possível obter maior número de dúzia de ovos com ovos mais leves.

Apesar do menor peso do ovo entre as aves leves, nelas verificou-se maior peso da gema e maior porcentagem de gema e unidades Haugh do que nas semipesadas, indicando que as aves leves depositam mais gema por peso do ovo e apresentam melhor qualidade interna quando comparadas às semipesadas (Tab. 5, 6 e 7). 
Tabela 4. Consumo de ração (CR), conversão por dúzia de ovos (CDO), conversão por massa de ovos (CMO) e porcentagem de ovos produzidos (POP) segundo a porcentagem de adição de met+cis na ração de poedeiras leves (L) e semipesadas (SP), no período de sete a 12 semanas de idade

\begin{tabular}{|c|c|c|c|c|c|c|c|c|}
\hline \multirow{3}{*}{$\begin{array}{c}\text { Met+cis } \\
(\%)\end{array}$} & \multicolumn{8}{|c|}{ Características } \\
\hline & \multicolumn{2}{|c|}{ CR } & \multicolumn{2}{|c|}{$\mathrm{CDO}$} & \multicolumn{2}{|c|}{$\mathrm{CMO}$} & \multicolumn{2}{|c|}{ POP } \\
\hline & $\mathrm{L}$ & SP & $\mathrm{L}$ & SP & $\mathrm{L}$ & SP & $\mathrm{L}$ & SP \\
\hline 0,471 & 100,02 & 102,77 & 1,30 & 1,36 & 1,81 & 1,88 & 92,03 & 90,84 \\
\hline 0,541 & 100,57 & 103,97 & 1,29 & 1,33 & 1,78 & 1,84 & 93,46 & 93,50 \\
\hline 0,611 & 101,53 & 103,12 & 1,32 & 1,36 & 1,79 & 1,84 & 94,92 & 92,50 \\
\hline 0,681 & 102,23 & 103,58 & 1,29 & 1,36 & 1,80 & 1,81 & 95,03 & 94,10 \\
\hline 0,751 & 98,71 & 102,58 & 1,26 & 1,29 & 1,79 & 1,77 & 94,11 & 95,62 \\
\hline Média & $100,6 b$ & $103,2 \mathrm{a}$ & $1,29 b$ & $1,34 \mathrm{a}$ & $1,79 a$ & $1,83 \mathrm{a}$ & $93,91 \mathrm{a}$ & $93,31 \mathrm{a}$ \\
\hline \multicolumn{9}{|c|}{ Efeito } \\
\hline Linear & ns & ns & ns & $\mathrm{ns}$ & ns & ns & ns & ns \\
\hline Quadrático & ns & ns & ns & ns & $\mathrm{ns}$ & ns & ns & ns \\
\hline Interação & \multicolumn{2}{|c|}{ ns } & \multicolumn{2}{|c|}{ ns } & \multicolumn{2}{|c|}{ ns } & \multicolumn{2}{|c|}{$\mathrm{ns}$} \\
\hline $\mathrm{CV}(\%)$ & \multicolumn{2}{|c|}{2,19} & \multicolumn{2}{|c|}{4,28} & \multicolumn{2}{|c|}{3,57} & \multicolumn{2}{|c|}{1,93} \\
\hline
\end{tabular}

Valores seguidos por letras diferentes na mesma linha diferem entre si pelo teste $\mathrm{F}(\mathrm{P}<0,05), \mathrm{ns}(\mathrm{P}>0,05)$.

Tabela 5. Qualidade dos ovos segundo a porcentagem de adição de met+cis na ração de poedeiras leves (L) e semipesadas (SP), no período de sete a 12 semanas de idade

\begin{tabular}{|c|c|c|c|c|c|c|}
\hline \multirow{3}{*}{$\begin{array}{c}\text { Met+cis } \\
(\%)\end{array}$} & \multicolumn{6}{|c|}{ Características } \\
\hline & \multicolumn{2}{|c|}{$\%$ gema } & \multicolumn{2}{|c|}{ \% albúmen } & \multicolumn{2}{|c|}{$\%$ casca } \\
\hline & $\mathrm{L}$ & SP & $\mathrm{L}$ & SP & $\mathrm{L}$ & SP \\
\hline 0,471 & 25.4 & 24.8 & 63.9 & 64.2 & 10.7 & 11.0 \\
\hline 0,541 & 25,1 & 24,3 & 64,1 & 65,1 & 10,8 & 10,5 \\
\hline 0,611 & 25,3 & 24,4 & 63,9 & 64,7 & 10,8 & 10,9 \\
\hline 0,681 & 25,5 & 23,9 & 63,6 & 65,3 & 10,8 & 10,8 \\
\hline 0,751 & 25,0 & 24,2 & 64,1 & 65,7 & 10,9 & 10,1 \\
\hline Média & $25,3 \mathrm{a}$ & $24,3 b$ & $63,9 b$ & $65,0 \mathrm{a}$ & $10,8 \mathrm{a}$ & $10,7 \mathrm{a}$ \\
\hline \multicolumn{7}{|c|}{ Efeito } \\
\hline \multirow{2}{*}{$\begin{array}{l}\text { Linear } \\
\text { Quadrático }\end{array}$} & ns & ns & $* *$ & ns & ns & ns \\
\hline & ns & $\mathrm{ns}$ & ns & $\mathrm{ns}$ & ns & ns \\
\hline Interação & \multicolumn{2}{|c|}{ ns } & \multicolumn{2}{|c|}{ ns } & \multicolumn{2}{|l|}{$\mathrm{ns}$} \\
\hline $\mathrm{CV}(\%)$ & \multicolumn{2}{|c|}{3,93} & \multicolumn{2}{|c|}{1,83} & \multicolumn{2}{|c|}{3,96} \\
\hline
\end{tabular}

Valores seguidos por letras diferentes na mesma linha diferem entre si pelo teste $\mathrm{F}(\mathrm{P}<0,05)$.

Tabela 6. Qualidade dos ovos segundo a porcentagem de adição de met+cis na ração de poedeiras leves (L) e semipesadas (SP), no período de sete a 12 semanas de idade

\begin{tabular}{|c|c|c|c|c|c|c|c|c|}
\hline \multirow{3}{*}{$\begin{array}{l}\text { Met+cis } \\
(\%)\end{array}$} & \multicolumn{8}{|c|}{ Características } \\
\hline & \multicolumn{2}{|c|}{ Peso do ovo } & \multicolumn{2}{|c|}{ Peso dagema } & \multicolumn{2}{|c|}{ Peso do albúmen } & \multicolumn{2}{|c|}{ Peso da casca } \\
\hline & $\mathrm{L}$ & SP & $\mathrm{L}$ & SP & $\mathrm{L}$ & SP & $\mathrm{L}$ & SP \\
\hline 0,471 & 60,0 & 60.3 & 15.2 & 14.9 & 38.4 & 38.7 & 6.44 & 6.63 \\
\hline 0,541 & 60,3 & 60,3 & 15,1 & 14,7 & 38,7 & 39,3 & 6,52 & 6,34 \\
\hline 0,611 & 59,8 & 60,5 & 15,2 & 14,8 & 38,2 & 39,1 & 6,44 & 6,61 \\
\hline 0,681 & 59,6 & 60,8 & 15,2 & 14,5 & 37,9 & 39,7 & 6,45 & 6,58 \\
\hline 0,751 & 58,5 & 60,6 & 14,6 & 14,6 & 37,4 & 39,8 & 6,40 & 6,13 \\
\hline Média & $59,6 b$ & $60,5 a$ & $15,1 \mathrm{a}$ & $14,7 \mathrm{~b}$ & $38,1 \mathrm{~b}$ & $39,3 a$ & $6,45 a$ & $6,46 a$ \\
\hline \multicolumn{9}{|c|}{ Efeito } \\
\hline Linear & ns & ns & ns & $\mathrm{ns}$ & $\mathrm{ns}$ & ns & ns & ns \\
\hline Quadrático & $* *$ & ns & $\mathrm{ns}$ & ns & ns & $\mathrm{ns}$ & ns & ns \\
\hline Interação & \multicolumn{2}{|c|}{ ns } & \multicolumn{2}{|c|}{$\mathrm{ns}$} & \multicolumn{2}{|c|}{$\mathrm{ns}$} & \multicolumn{2}{|c|}{ ns } \\
\hline $\mathrm{CV}(\%)$ & \multicolumn{2}{|c|}{2,07} & \multicolumn{2}{|c|}{3,31} & \multicolumn{2}{|c|}{3,61} & \multicolumn{2}{|c|}{3,65} \\
\hline
\end{tabular}

Valores seguidos por letras diferentes na mesma linha diferem entre si pelo teste $\mathrm{F}(\mathrm{P}<0,05)$. 
Tabela 7. Qualidade dos ovos segundo a porcentagem de adição de met+cis na ração de poedeiras leves (L) e semipesadas (SP), no período de sete a 12 semanas de idade

\begin{tabular}{|c|c|c|c|c|c|c|}
\hline \multirow{3}{*}{$\begin{array}{l}\text { Met+cis } \\
(\%)\end{array}$} & \multicolumn{6}{|c|}{ Características } \\
\hline & \multicolumn{2}{|c|}{ UH } & \multicolumn{2}{|c|}{ IG } & \multicolumn{2}{|c|}{ IA } \\
\hline & $\mathrm{L}$ & SP & $\mathrm{L}$ & SP & $\mathrm{L}$ & SP \\
\hline 0,471 & 95,5 & 92,4 & 4,60 & 4,80 & 1,30 & 1,13 \\
\hline 0,541 & 97,7 & 93,6 & 4,59 & 4,81 & 1,37 & 1,19 \\
\hline 0,611 & 94,8 & 92,7 & 4,64 & 4,78 & 1,28 & 1,18 \\
\hline 0,681 & 95,5 & 92,4 & 4,72 & 4,75 & 1,29 & 1,16 \\
\hline 0,751 & 95,0 & 92,4 & 4,66 & 4,69 & 1,27 & 1,18 \\
\hline Média & $95,7 \mathrm{a}$ & $92,7 b$ & $4,64 b$ & $4,76 a$ & $1,30 \mathrm{a}$ & $1,17 b$ \\
\hline \multicolumn{7}{|c|}{ Efeito } \\
\hline Linear & $\mathrm{ns}$ & $\mathrm{ns}$ & ns & ns & ns & ns \\
\hline Quadrático & ns & ns & ns & ns & ns & ns \\
\hline Interação & \multicolumn{2}{|c|}{$\mathrm{ns}$} & \multicolumn{2}{|c|}{ ns } & \multicolumn{2}{|c|}{$\mathrm{ns}$} \\
\hline $\mathrm{CV}(\%)$ & \multicolumn{2}{|c|}{2,08} & \multicolumn{2}{|c|}{2,79} & \multicolumn{2}{|c|}{5,43} \\
\hline
\end{tabular}

Valores seguidos por letras diferentes na mesma linha diferem entre si pelo teste $\mathrm{F}(\mathrm{P}<0,05)$.

A quantidade de met+cis fornecida na fase de cria influenciou o peso dos ovos das aves leves $(\mathrm{P}<0,05)$ e a porcentagem de albúmen. $\mathrm{O}$ maior peso dos ovos foi obtido com a inclusão de $0,550 \%$ de met+cis na ração, e a porcentagem de albúmen aumentou linearmente com a inclusão de met+cis na ração. As demais características produtivas na fase de produção não foram influenciadas pela inclusão de met+cis na ração na fase de cria. Estes resultados indicam que, independentemente da quantidade utilizada na fase de cria, a qualidade do ovo não foi afetada na fase de produção. A deficiência nutricional em aminoácidos sulfurosos durante a fase de cria não foi suficiente para afetar o desenvolvimento reprodutivo, pois este não envolve somente a produção mas, também, a qualidade do ovo produzido. Estes resultados conflitam com os dados de Silva et al. (2009), os quais verificaram que a porcentagem de inclusão de met+cis da dieta durante o período de cria de cinco a 11 semanas de idade influenciou o desempenho das aves e a produção, o peso e a massa do ovo, bem como a conversão por massa de ovo na fase de produção

Existem poucos trabalhos determinando as exigências nutricionais de aminoácidos sulfurosos na fase de crescimento, em que se avaliam os efeitos durante a fase de postura. Estudos como esse seriam importantes para assegurar melhor escolha do nível de exigência, pois estariam baseados não só no desenvolvimento durante a fase de crescimento como também em toda a fase de produção, assegurando melhor estimativa da exigência nutricional.

Aves leves alimentadas com porcentagens mais elevadas de met+cis durante a fase inicial de criação apresentaram, durante a postura, maior número de ovos com defeito. Provavelmente, estes resultados se devem ao maior peso corporal das aves alimentadas com porcentagens mais elevadas de met+cis, o que favoreceu o aumento no peso de ovos, que, por sua vez, associado à precocidade de início de postura, acarretou em maior incidência de ovos sem casca, quebrados e de duas gemas. Este efeito não foi observado nas aves semipesadas, em razão da provável menor variação de peso corporal ocorrida entre os tratamentos, pois houve variação de, no máximo, $2,21 \%$ entre os tratamentos para as aves semipesadas, e variação de até $4,18 \%$ entre os tratamentos das aves leves.

Os valores estimados de exigência em met+cis totais em frangas de reposição leves, na fase de cria (sete a 12 semanas de idade), de acordo com o modelo de regressão, foram de 0,710 e 0,702\%, respectivamente, para o ganho de peso e conversão alimentar. Nas aves semipesadas, as exigências em met+cis foram estimadas em 0,703 e $0,706 \%$, para ganho de peso e conversão alimentar, respectivamente.

Considerando a digestibilidade da metionina + cistina de $90 \%$ (Rostagno et al., 2000), as exigências em met+cis digestíveis para frangas leves de reposição na fase de sete a 12 semanas de idade foram estimadas em, respectivamente, 
0,639 e $0,632 \%$ para ganho de peso e conversão alimentar; e para semipesadas 0,633 e $0,635 \%$ para ganho de peso e conversão alimentar, respectivamente.

A variação encontrada entre as exigências de met+cis de aves leves e semipesadas, neste trabalho, foi de apenas 0,99\%, sugerindo somente uma exigência para ambas as linhagens.

A relação met+cis:lisina total foi de 0,70 para frangas leves e de 0,69 para frangas semipesadas. Estas relações são menores que a recomendada por Rostagno et al. (2011), de 0,80 para ambas as linhagens. Estes autores recomendam 0,552\% de met+cis total para frangas de reposição leves de sete a 12 semanas de idade e 0,543\% para frangas de reposição semipesadas nesta mesma idade.

Ao se considerar a fase de produção (22 a 33 semanas de idade), não se verificou efeito da inclusão de níveis de met+cis na ração, tanto nas aves leves como nas semipesadas, o que sugere a possibilidade de se utilizarem níveis mais baixos de met+cis na fase inicial de criação, sem afetar a produção e a qualidade dos ovos.

\section{CONCLUSÃO}

Os níveis de metionina+cistina recomendados para aves de reposição, leves e semipesadas, no período de sete a 12 semanas de idade, são de $0,710 \%$ de met+cis $(0,639 \%$ de met+cis digestível) e de $0,706 \%$ de met+cis $(0,635 \%$ de met+cis digestível), respectivamente.

\section{REFERÊNCIAS}

BAKER, D.H. Problems and pitfalls in animal experiments designed to establish dietary requirements for essential nutrients. J. Nutr., v.116, p.2339-2349, 1986.
BREDFORD, M.R.; SUMMERS, J.D. Influence of the ratio of essential to non-essential aminoacids on performance and carcass composition of the broiler chick. Br. Poult. Sci., v.26, p.483-491, 1985.

KWAKKEL， R.P.; KONING, F.L.S.M.; VERSTEGEN, M.W.A. et al. Effect of method and phase of nutrient restriction during rearing on productive performance of light hybrid pullets and hens. Br. Poult. Sci., v.32, p.747-761, 1991.

ROMBOLA, L.G.; FARIA, D.E.; DEPONTI, B.J. et al. Fontes de metionina em rações formuladas com base em aminoácidos totais ou digestíveis para frangas de reposição leves e semipesadas. Rev. Bras. Zootec., v.37, p.19901995, 2008.

ROSTAGNO, H.S.; ALBINO, L.F.T.; DONZELE, J.L. et al. Tabelas brasileiras para aves e suínos; composição de alimentos $e$ exigências nutricionais. 1.ed. Viçosa-MG: UFV, Departamento de Zootecnia, 2000. 141p.

ROSTAGNO, H.S.; ALBINO, L.F.T.; DONZELE, J.L. et al. Tabelas brasileiras para aves e suínos; composição de alimentos $e$ exigências nutricionais. 3.ed. Viçosa-MG: UFV, Departamento de Zootecnia, 2011. 252p.

SILVA, E.L.; SILVA, J.H.V.; BERTECHINI, A.G. et al. Exigência de metionina+cistina para aves de reposição leves e semipesadas de 1 a 4 semanas de idade alimentadas com rações farelada e triturada. Rev. Bras. Zootec., v.38, p.500-507, 2009.

SISTEMA de Análises Estatísticas e Genéticas (SAEG). Versão 8.0. Viçosa, MG. UFV, 1999. $142 \mathrm{p}$. 